\title{
PROSPEK PENGOLAHAN MENGKUDU MENJADI SARI MORINDA DI KABUPATEN OKU TIMUR (Studi Kasus Kelompok Pangan Olahan Nay-Nay).
}

\author{
(Wardi Saleh)
}

\begin{abstract}
The purpose of this research were to : (1) To know the cost and income of processing mengkudu become morinda juice in Regency OKU East, (2) To know value added of processing mengkudu become sari morinda in Regency OKU East, (3) To know feasibility of processing Mengkudu become morinda juice in Kabpaten OKU East. This research was conducted in Srikaton Village, Buay Madang Timur District, East OKU Regency. This research was conducted in April - May 2015 with the method of case study conducted directly to one farmer who do the making of noni juice in Srikaton Village. This study found that the cost of processing production to morindan mengkuduku morindan in Srikaton Village Buay Madang District East OKU Regency is Rp 351.500 / production process. While the income of Rp 898,500 / production process, the amount of added value obtained from the production value minus the cost between Rp 991.500 / production process and processing mengkudu become morinda juice deserve to be developed dengang NPV criteria present value of home industry juice morinda at an interest rate of $18 \% \mathrm{Rp} 4.715 .86$ at the highest interest rate ie 36\% of Rp-260.924maka value of NPV> O feasible business to dilanjutka. The value of Net B / C at the value of NPV that has been discount factor on the home industry business extract of morinda obtained at 1.30 and IRR of $35 \%$.
\end{abstract}

Key Words : Agriculture Agribusiness, Noni fruit processing, Income.

\section{PENDAHULUAN}

\section{A. Latar Belakang}

Indonesia terletak didaerah tropik dan memiliki keanekaragaman hayati yang cukup tinggi bila dibandingkan dengan daerah beriklim subtropik (iklim sedang) dan iklim kutub. Oleh karena itu Indonesia memiliki berjuta - juta jenis tanaman, baik yang sudah dikenal (teridentifikasi) maupun yang belum dikenali oleh manusia. Masyarakat Indonesia secara umum hanya mengetahui $\pm 10 \%$ saja manfaat dari berbagai tanaman yang ada di sekitarnya. Salah satu dari berbagai tanaman itu adalah mengkudu (Morinda citrifolia L.) yang banyak tumbuh disekitar kita, namun pemanfaatannnya belum optimal (Waha , 2002).

Mengkudu atau keumeudee (Aceh); pace, kemudu, kudu (Jawa); cangkudu (Sunda); kodhuk (Madura); tibah (Bali) berasal daerah Asia Tenggara, tergolong dalam famili Rubiaceae. Nama lain untuk tanaman ini adalah noni (Hawaii), nono (Tahiti), nonu (Tonga), ungcoikan (Myanmar) dan ach (Hindi).

Tanaman ini tumbuh di dataran rendah hingga pada ketinggian $1500 \mathrm{~m}$. Tinggi pohon mengkudu mencapai $3-8 \mathrm{~m}$, memiliki bunga bongkol berwarna putih. Buahnya merupakan buah majemuk, yang masih muda berwarna hijau mengkilap dan memiliki totol - totol, dan ketika sudah tua berwarna putih dengan bintik - bintik hitam. Secara tradisional, masyarakat menggunakan buah mengkudu sebagai sayur dan rujak. Daunnya juga digunakan sebagai salah satu bahan nicah peugaga yang sering muncul sebagai menu wajib buka puasa. Karena itu, mengkudu sering ditanam di dekat rumah di pedesaan pada masyarakat. Selain itu mengkudu juga sering digunakan sebagai bahan obat-obatan (Tjitrosoepomo, 1991).

Dalam kehidupan sehari-hari kebanyakan masyarakat awam kurang mengetahui akan banyaknya manfaat dari tanaman mengkudu. Biasanya masyarakat hanya menggunakan daun mengkudu untuk diolah sebagai sayur dan buahnya banyak terbuang percuma, karena sebagai buah rasanya kurang begitu enak. Keadaan perekonomian Indonesia yang dilanda krisis ekonomi sejak beberapa tahun lalu, menyebabkan naiknya berbagai harga bahan pokok maupun obat-obatan. Sehingga masyarakat banyak yang merasa kesulitan untuk mendapatkan obat - obatan dengan harga yang relatif murah dan aman dikonsumsi, sedangkan obat - obata harganya mahal banyak mepunyai efek samping. (Waha, 2005).

Pada musim pancaroba seperti sekarang ini banyak penyakit yang bermunculan yang tidak dapat kita perkirakan sebelumnya, salah satunya adalah batuk. Disamping karena musim pancaroba, batuk juga dapat disebabkan oleh makanan yang kita konsumsi. Batuk adalah penyakit yang tidak 
pandang apapun, dari balita sampai orang tua, dari orang miskin sampai orang kaya semua bisa saja terserang batuk. Batuk merupakan refleks normal yang berfungsi untuk melindungi paru - paru dari aspirasi. Mekanisme batuk terdiri dari 3 fase yaitu fase inspirasi, fase kompresi dan fase ekspirasi. Penyebab batuk dapat berupa penyakit atau proses yang merangsang refleks batuk.

Salah satu obat yang bisa mengurangi batuk, hipertensi dan bisa mennyembuhkan magh adalah buah mengkudu, dengan cara mengkudu yang sudah masak dicuci terlebih dahulu kemudian diperas diambil airnya disaring dan dicampurka 7 Liter air,1 Kg gula premium, Jika mengkudu belum matang dipotong kecil-kecil terlebeh dahulu kemudian iris kecil Bahan-bahan lalu dicampurkan kedalam air, untuk touge/kecambah setelah cambah rebus diambil airnya kemudian dicampurkan. Setelah semua dicampurkan lalu didinginkan kemudian masukkan ragi kue (fermipan) kemudian tutup rapat - rapat, bisa langsung dikonsumsi untuk penggunaan dalam waktu lama harus difermentasikan.

Dari waktu kewaktu, industri pengolahan buah mengkudu, baik industri besar maupun industri (Home industry), sebagai gambaran, sampai perkembangan tahun 2012 diwiliyah jabodetabek jumlah industri pengolahan buah mengkudu mencapai angka 50. Kondisi seperti ini membuatkebutuhan pasokan buah mengkudu bertambah. Masalahnya, kebutuhan pemasok bahan baku sampai sekarang masih mengandalkan pemerintah buah mengkudu dari tanaman liar tidak mengherankan jika pasokan jus buah mengkudu tidak terpenuhi untuk memproduksi 300 liter buah mengkudu, home industri , 2500 liter jus murni atau setara dengan 15 ton buah segar hasil pemasokan dari penyuplaian tanaman buah mengkudu sekitar 50 - $100 \mathrm{~kg}$. Untuk itu kekurangan pasokan buah mengkudu mulai merangkul petani disekitar wilayah jawa barat, lampung dan jawa tengah dengan sistem pola kemitraan.

Desa Srikaton merupakan salah satu desa yang ada di Kabupaten OKU Timur. Mata pencarian penduduknya beragam, mulai dari petani, pedagang, buruh, pegawai swasta dan PNS. Melihat peluang pasar yang masih sedikit untuk itu responden mulai merintis usaha sari mengkudu guna ikut meramaikan pemasaran sari mengkudu khususnya di pasar Rawabening. Sedangkan proses pembuatan sari mengkudu setelah disediakan bahan - bahan dan alat kemudian dilakukan proses fermentasi setelah itu di dingikan lalu dilakukan proses pembotolan dan pemekingan.

Dengan berbagai alasan di atas perlu dilakukan penelitian tentang usaha untuk mengembangkan khasiat buah Mengkudu sebagai alternatif anti bakteri, khususnya bakteri penyebab penyakit batuk. Sehingga nantinya bila menunjukkan hasil positif, dapat diketahui bahwa buah Mengkudu dapat dijadikan alternatif obat batuk, hipertensi dan magh.

\section{B. Rumusan Masalah}

1. Berapa biaya dan pendapatan pada pengolahan mengkudu menjadi sari morinda di Kabupaten OKU Timur.

2. Berapa nilai tambah dari proses pembuatan mengkudu menjadi sari morinda di Kabupaten OKU Timur.

3. Apakah usaha pengolahan mengkudu menjadi sari morinda di Kabupaten OKU Timur layak untuk dikembangkan .

\section{Tujuan dan Kegunaan}

1. Untuk mengetahui biaya dan pendapatan pada pengolahan mengkudu menjadi sari morinda di Kabupaten OKU Timur.

2. Untuk mengetahui nilai tambah pengolahan mengkudu menjadi sari morinda di Kabupaten OKU Timur .

3. Untuk mengetahui kelayakan pengolahan mengkudu menjadi sari morinda di Kabpaten OKU Timur.

\section{Model Pendekatan}

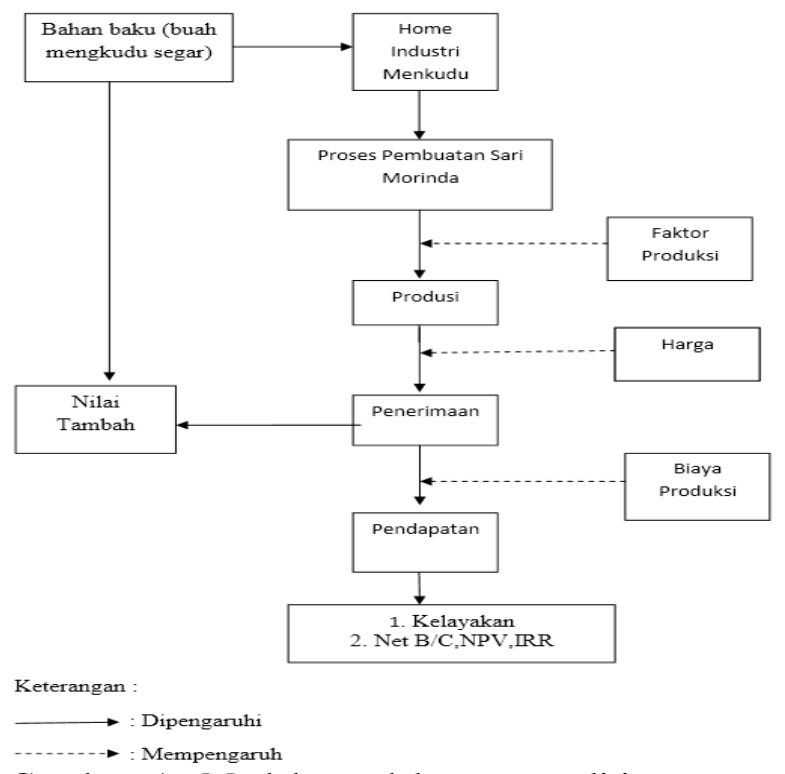

Gambar 1. Model pendekatan penelitian secara diagramatik. 


\section{METODOLOGI PENELITIAN}

\section{A. Tempat dan Waktu}

Penelitian ini dilaksanakan pada Bulan April - Mei 2015 di Desa Srikaton Kecamatan Buay Madang Timur Kabupaten OKU Timur Sumatera Selatan.

\section{B. Metode Penelitian}

Metode penelitian yang digunakan adalah study kasus yang dilakukan secara langsung kepada satu orang petani yang melakukan pembuatan sari mengkudu di Desa Srikaton. Study kasus adalah penelitian mendalam mengenai unit sosial tertentu yang hasilnya merupakan gambaran yang lengkap dan terorganisasi mengenai unit tersebut. Tujuan penelitian kasus ini adalah untuk mempelajari secara intensif latar belakang keadaan sekarang dan interaksi lingkungan unit sosial. Metode ini digunakan untuk memperoleh data yang berhungan dengan pembuatan sari mengkudu, biaya yang dikeluarkan dan pendapatan yang diperoleh (Yin, 2008).

\section{Metode Penarikan Contoh}

Metode pengumpulan data yang digunakan dalam penelitian ini terdiri dari data primer dan sekunder. Data primer yang dikumpulkan adalah mengenai identitas responden, tingkat pendidikan responden, lama usaha yang dikelola, teknik pembuatan sari mengkudu dan pemasaran sari mengkudu serta data-data penunjang lain nya. Sedangkan data sekunder diperoleh dari penelitian meliputi keadaan umum daerah dan data lain yang dianggap perlu guna menunjang penelitian yang telah dilaksanakan (Nazir, 2003) .

Penarikan contoh yang di ambil pada studi kasus (Home industry sari mengkudu) ini hanya satu sampel di Desa Sri Katon Kecamatan Buay Madang dan hanya satu di Kabupaten OKU Timur.

\section{Metode Pengolahan Data}

Data yang dikumpulkan meliputi data primer dan data sekunder. Pengumpulan data primer diperoleh dari wawancara langsung dengan narasumber menggunakan daftar pernyataan (quisioner) yang telah disiapkan oleh penulis. Sedangkan data skunder diperoleh dari penelitian meliputi keadaan umum daerah dan data lain yang dianggap perlu guna menunjang penelitian yang telah dilaksanakan.

1. Untuk menjawab tujuan nomor satu penulis akan menggunakan metode studi pustaka baik data yang diperoleh dilapangan maupun data dari media cetak. Media elektronik dan informasi yang di dapat penulis.

2. Untuk mengetahui biaya produksi yang dikeluarkan oleh responden dilokasi penelitian akan dihitung dengan menggunakan rumus sebagai berikut (Soekarwati, 1995):

$$
\mathrm{TC}=\mathrm{FC}+\mathrm{VC}
$$

TC : Total Cost/Biaya Total (Rp)

FC : Fixed Cost/ Biaya Tetap (Rp)

VC: Variable Cost/ Biaya tidak tetap (Rp)

3. Untuk mengetahui besarnya penerimaan dengan menggunakan rumus

$$
\mathrm{TR}=\mathrm{P} \text { X Y }
$$

Dimana :

TR : Total Revenue/ total penerimaan ( $\mathrm{Rp})$

$\mathrm{P}$ : Price/ Harga (Rp)

Y : Yield/ Hasil/ Produksi (Ton/ Ha)

4. Perhitungan pendapatan usahatani dapatdilakukan dengan pendekatan:

$$
\mathrm{I}=\mathrm{TR}-\mathrm{TC}=
$$

Dimana:

I : Income/Pendapatan (Rp)

$\mathrm{Tr}$ : Total Revenue/Total Penerimaan (Rp)

Tc : Total Cost/Total biaya produksi (Rp)

5. Untuk mengetahui keuntungan Home Industri proses pengolahan sari morinda ini menggunakan analisis R/C Ratio dengan rumus sebagai berikut :

$$
\mathrm{R} / \mathrm{C}=\frac{\mathrm{TR}}{\mathrm{TC}}
$$

Keputusan dalam analisis sebagai berikut :

a.Bila $\mathrm{R} / \mathrm{C}$ ratio $<1$ artinya penerimaan lebih kecil dari total biaya, sehingga Home industry tidak efisien (Rugi).

b. Bila $\mathrm{R} / \mathrm{C}$ ratio $=1$ artinya peneriman sama dengan besarnya total biaya. Sehingga usahahome industri impas (Balik Modal/tidak untungdan tidak rugi/Break event point).

c.Bila $\mathrm{R} / \mathrm{C}$ ratio > 1 artinya penerimaan lebih besar dari total biaya, sehingga home industi tersebut efisien (menguntungkan)

6. Untuk Mencari Nilai Tambah dengan rumus sebagai berikut (Yudi, 2010):

$$
\text { NT= TR-IC. }
$$

\section{Keterangan:}

a.NT: (Nilai Tambah)

b.TR: (Total Penerimaan)

c. IC: (Biaya antara)

7. Untuk menganalisis kelayakan usaha secara finansial, dilihat dari Nilai Kini Bersih (Net Present Value), IRR dan Net B/C, dengan rumus sebagai berikut : 
a. Nilai Kini Bersih (Net Present Value) (Husein Umar, 2009)

$$
\mathrm{NPV}=\sum_{i=1}^{n} \frac{\mathrm{Bt}-\mathrm{Ct} .}{(1+\mathrm{i})^{\mathrm{n}}}
$$

Keterangan:

NB $:$ Net Benefit $=$ Benefit - cost

I : Intrest (tingkat suku bunga)

$\mathrm{N}$ :Time/rentang waktu (tahun ke $1,2,3$...dst)

b. IRR (Internal Rate of Retrun/Laju keberhasilan Usaha), dengan rumus (Ibrahim, 2003) :

$$
\mathrm{IRR}=\mathrm{i}_{1}+\frac{N P V 1}{N P V 1-N P V 2} X\left(\mathrm{i}_{2} \mathrm{i}_{1}\right) \text {. }
$$

Keterangan:

$\mathrm{NPV}_{1} \quad$ : Net present value yang bernilai positif.

$\mathrm{NPV}_{2} \quad$ : Net present value yang bernilai negatif

$\mathrm{i}_{1} \quad$ :Discount rate yang menghasilkan $\mathrm{NPV}_{1}$

$\mathrm{i}_{2} \quad$ : Discount rate yang menghasilkan NPV 2

c. Nilai Net B/C (B/C ratio antarmasa ) dengan rumus (Gittinger, 1986) :

Net $\mathrm{B} / \mathrm{C}=\frac{\underset{\sum(B-C)}{(1+I) t(+)}}{\begin{array}{c}\sum(B-C) \\ (1+i) t(-)\end{array}}$

Keterangan:

B positif : Manfaat (laba) bersih dengan nilai positif

B negatif : Manfaat (laba) bersih dengan nilai negatif

$\mathrm{r} \quad$ : Discount rate (tingkat bunga \%)

t : Tahun

Dengan Kriteria:

Net $B / C>1$, Maka usaha tersebut layak

Net $B / C<1$, Maka usaha tersebut tidak layak

Net $B / C=1$, Maka usaha tersebut impas

\section{HASIL DAN PEMBAHASAN}

\section{Analisi Usaha Pengolahan Mengkudu menjadi Sari Morinda.}

Biaya merupakan salah satu hal penting yang harus diperhatikan dalam usaha pembuatan sari morinda, karena biaya dapat menunjukan kondisi usaha yang dijalankan. Biaya adalah pengorbanan sumber ekonomi yang diukur dalam satuan uang yang telah terjadi atau kemungkinan akan terjadi untuk mencapai tujuan tertentu (Mulyadi, 2007). Biaya yang terjadi dalam home industri sari morinda terdiri dari dua komponen, yaitu biaya tetap dan biaya variabel.

Menurut Hanafie (2010), biaya tetap adalah semua jenis biaya yang besar kecilnya tidak tergantung pada besar kecilnya produksi. Yang termasuk dalam komponen biaya tetap, misalnya sewa tanah yang merupakan uang atau pajak yang penentunya berdasarkan luas lahan. Jumlah biaya tetap adalah konstan. Sedangkan biaya variabel adalah biaya yang besar kecilnya berhungan langsung dengan besar kecilnya produksi seprti bahan - bahan pembuatan sari morinda dan tenaga kerja.

\section{Analisis Biaya Produksi}

Biaya produksi berfungsi sebagai gambaran untuk mengetahui tingkat produksi yang dilakukan, biaya produksi terdiri dari biaya tetap dan biaya variabel. Biaya tetap adalah biaya yang tidak habis dalam satu kali proses produksi yang meliputi biaya sewa lahan dan penyusutan alat. Sedangkan biaya variabel adalah biaya yang besar kecinya tergantung kepada besar kecilnya produksi pengolahan mengkudu menjadi sari morinda. Biaya variabel dalam pengolahan mengkudu menjadi sari morinda meliputi biaya sarana produksi dan tenaga kerja. Keadaan biaya produksi pada tabel dibawah ini :

Tabel 1. Total Biaya Produksi Pengolahan Mengkudu Menjadi Sari Morinda di Desa Srikaton Kecamatan Buay Madang Kabupaten OKU Timur.

\begin{tabular}{llr}
\hline $\mathrm{N}$ & \multicolumn{1}{c}{ Jenis Biaya } & \multicolumn{1}{c}{ Nilai (Rp/proses) } \\
$\mathrm{o}$ & & \\
\hline 1 & Biaya Tetap (FC) & \\
$\cdot$ & & 50.000 \\
& -Sewa Tempat & 52.900 \\
\hline -Penyusutan & 102.900 \\
\hline & Jumlah
\end{tabular}

Sumber : Analisis Data Primer Bulan April 2015.

\begin{tabular}{llr}
\hline $\mathrm{N}$ & Jenis Biaya & \multicolumn{1}{c}{ Nilai (Rp/proses) } \\
$\mathrm{o}$ & & \\
\hline 1 & Biaya Variabel & 351.000 \\
& Biaya Tetap & 102.900 \\
\hline & Jumlah Total & 453.900 \\
\hline
\end{tabular}

Sumber : Analisis Data Primer Bulan April 2015.

Tabel 2. Komposisi Biaya Variabel Usaha Pengolahan Mengkudu Menjadi Sari Morinda di di Desa Srikaton Kecamatan Buay Madang Kabupaten OKU Timur Provinsi Sumatera Selatan, 2015.

NO Uraian Jumlah (Rp)

1. Mengkudu 5.000

2. Gula Premium 70.000 
3. Seray

4. Fermipan

5. Kunyit kuning

6. Binaho

7. Gingseng Jawa

8. Air

9. Gas

10. Plastik Pres

11. Lebel Gambar

12. Sewa Tempat

13. Transpotasi

14. Tenaga Kerja

90.000

15. Botol

37.500

Total Biaya Variabel

351.500

Sumber: Analisis Data Primer Bulan April 2015.

Berdasarkan tabel di atas dapat diketahui bahwa biaya produksi yang dikeluarkan dalam proses pembuatan sari morinda sebesar $\mathrm{Rp}$. 453.900 / proses, dimana dalam satu kali proses dibutuhkan waktu \pm 30 hari. Adapun biaya tetap sebesar Rp. 102.900 / proses dan biaya variabel sebesar Rp. 351.500. Sedangkan upah tenagga kerja persatu kali proses sebesar Rp 90.000.

Suatu proses produksi akan berjalan apabila ada biaya yang dikeluarkan dalam proses produksi serta membayar menjadi produksi. Adapun biaya produksi dikelompokkan menjadi dua yaitu Biaya Tetap ?(Fixed Cost) dan Biaya Variabel (Variable Cost).

\section{Biaya Operasional}

Biaya operasional yang dikeluarkan untuk usaha pengolahan mengkudu menjadi sari

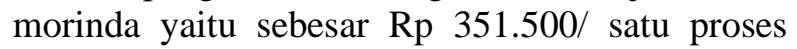
produksi. Jadi biaya bahan bakunya yang dikeluarkan terdiri dari pembelian mengkudu sebesar Rp 5.000, pembelian gula premium sebesar Rp 70.000, pembelian seray sebesar Rp 6.000, pembelian fermipan sebesar $\mathrm{Rp}$ 5.000, pembelian kunyit kuning sebesar Rp 6.000, pembelian daun binaho sebesar $\mathrm{Rp}$ 6.000, pembelian gingseng jawa sebesar Rp 7.000, pembelian air sebesar Rp 7.000, pembelian gas sebesar Rp 20.000, pembelian lebel produk sebesar Rp 12.5000, pembelian plastik pres sebesar Rp 12.500, pembelian botol sebesar Rp
37.500, biaya transfortasi sebesar Rp 17.000 serta biaya upah tenaga kerja sebesar Rp 90.000 .

\section{Produksi dan Penerimaan}

Produksi adalah suatu kegiatan pengolahan bahan baku sehingga menjadi suatu produk yang dapat digunakan untuk kebutuhan. Jumlah sari morinda yang dihasilkan setiap satu kali proses produksi adalah 35 liter atau 125 botol dan dijual dengan harga Rp. 10.000/botol.

Sedangkan penerimaan adalah jumlah dari hasil produksi yang diperoleh dengan dikalikan harga jual. Penerimaan pengolahan sari morinda di Desa Srikaton sebesar Rp 1.250.000 persatu kali proses produksi. Tahun pertama memproduksi 1.375 botol, tahun kedua memproduksi 1.125 botol sedangkan tahun ketiga memproduksi 1.200 botol dengan harga perbotol $\mathrm{Rp}$ 1.250. Untuk mengetahui produksi dan penerimaan home industri sari morinda di Desa Srikaton pada tabel dibawah ini:

Tabe 3. Jumlah Produksi dan Penerimaan Pembuatan Sari Morinda di Desa Srikaton Kecamatan Buay Madang Kabupaten OKU Timur.

\begin{tabular}{llr}
\hline $\mathrm{N}$ & \multicolumn{1}{c}{ Uraian } & \multicolumn{1}{c}{ Uraian/Proses } \\
$\mathrm{o}$ & & \\
\hline 1 & Produksi & 125 Botol \\
2 & Harga & Rp 10.000 \\
3 & Penerimaan & Rp 1.250 .000 \\
\hline
\end{tabular}

Sumber: Analisis Data Primer Bulan April 2015.

\section{Pendapatan}

Pada home industri sari morinda yang dilakukan di Desa Srikaton di peroleh penerimaan dan pendapatan pada tabel dibawah ini :

Tabel 4. Pendapatan Home industry Sari Morinda di Desa Srikaton Kecamatan Buay Madang Kabupaten OKU Timur.

\begin{tabular}{|c|c|c|}
\hline $\begin{array}{l}\mathrm{N} \\
\mathrm{O}\end{array}$ & Uraian & Nilai (Rp/Proses) \\
\hline 1 & Produksi & 351.500 \\
\hline 2 & Penerimaan (TR) & 1.250 .000 \\
\hline 3 & Pendapatan (I) & 898.500 \\
\hline
\end{tabular}

Sumber: Analisis Data Primer Bulan April 2015.

Berdasarkan tabel diatas sari morinda dijual dalam kemasan botol $280 \mathrm{ml}$ produksi sari morinda dalam satu kali produksi menghasilkan 35 liter dan menjadi 125 botol. Sehingga mendapat penerimaan sebesar Rp. 1.250.000. 
Pendapatan sebesar Rp 898.500 dengan begitu usaha pembuatan sari morinda menguntungkan.. Sari morinda dijual langsung ke konsumen dan juga melayani pemesanan serta ada juga yang membeli melakukan proses pembuatan.

\section{Tingkat Keuntungan Pengolahan Sari Morinda.}

Hasil perhitungan kriteria investasi dapat digunakan sebagai bahan pertimbangan dalam mengabil keputusan penanaman modal. Kriteria investasi yang dapat digunakan : NPV, IRR, Net B/C. Keputusan yang timbul dari hasil analisis: menerima atau menolak, memilih salah satu beberapa proyek, atau menetapkan skala prioritas yang layak. (Ibrahim, 2009).

Pada pengolahan sari morinda yang dilakukan di Desa Srikaton diperoleh penerimaan dan pendapatan pada tabel dibawah ini :

Tabel 5.Tingkat kelayakan Home industry Sari Morinda di Desa Srikaton Kecamatan Buay Madang Kabupaten OKU Timur.

\begin{tabular}{clr}
\hline No & \multicolumn{1}{c}{ Uraian } & \multicolumn{1}{c}{ Nilai (Rp/Proses) } \\
\hline 1 & Penerimaan (Rp) & 1.250 .000 \\
2 & Total Biaya (Rp) & 351.500 \\
3 & R/C Ratio & 3,5 \\
\hline
\end{tabular}

Sumber: Analisis Data Primer Bulan April 2015.

Dari tabel diatas dapat diketahui bahwa : R/C Ratio yang didapat dalam satu kali proses produksi adalah 3,5 artinya untuk setiap Rp 1 yang diinvestasikan akan memberikan penerimaan sebesar Rp.2,5.

\section{Nilai Tambah}

Untuk menghitung nilai tambah digunakan rumus sebagai berikut :

$$
\mathrm{NT}=\mathrm{NP}-\mathrm{IC}
$$

Ket.:

$\mathrm{NT}=$ Nilai Tambah POC $(\mathrm{Rp})$

$\mathrm{NP}=$ Nilai Produksi (harga $\mathrm{x}$ jumlah produksi)

IC = Intermediate cost (biaya antara yaitu biaya produksi diluar tenaga kerja keluarga).

Menurut Hayami, 2010 untuk mencari nilai tambah:

Tabel 6. Nilai Tambah Home industry Sari Morinda di Desa Srikaton Kecamatan Buay Madang Kabupaten OKU Timur.

\begin{tabular}{llr}
\hline No & \multicolumn{1}{c}{ Uraian } & Nilai (Rp/Proses) \\
\hline 1 & Nilai Produksi & 1.250 .000 \\
2 & Biaya Antara & 261.500 \\
& & \\
3 & Nilai Tambah & 991.500
\end{tabular}

Sumber: Analisis Data Primer Bulan April 2015.
Dari tabel diatas dapat diketahui nilai produksi sebesar Rp 1.250.000, sedangkan biaya antara Rp 261.500. Nilai tambah yang diperoleh dalam setiap kali produksi sebesar Rp 991.500.

\section{Analisa Kelayakan Usaha Home industry Sari Morinda.}

\section{a. Analisa NPV}

Net Present Value (NPV) atau nilai sekarang bersih adalah analisis manfaat finansial yang digunakan untuk mengukur layak tidaknya suatu usaha dilaksanakan dilihat dari nilai sekarang (present value). Keuntungan dari suatu proyek adalah besarnya penerimaan dikurangi pembiayaan yang dikeluarkan. Dapat dikatakan bahwa NPV adalah selisih antara Present Value dari arus Benifit dikurangi Present Value PV dari arus biaya (Soekartawi, 1996).

Kriteria kelayakan dari proyek ini adalah: proyek layak jika NPV bertanda positif dan sebaliknya tidak layak jika NPV bertanda negatif.

Tabel 7. Analisis Net B/C, NPV dan IRR Home industry Sari Morinda di Desa Srikaton Kecamatan Buay Madang Kabupaten OKU Timur.

\begin{tabular}{llrrrr}
\hline & & \multicolumn{4}{c}{ TAHUN } \\
\cline { 3 - 6 } No & \multicolumn{1}{c}{ Uraian } & \multicolumn{1}{c}{ t0 } & t1 & \multicolumn{1}{c}{ t2 } & t3 \\
\hline 1 & Penerimaan & & & & \\
\hline 2 & $\begin{array}{l}\text { Biaya-biaya } \\
\text { a.investasi awal } \\
\text { b.total biaya produksi }\end{array}$ & 22.336 .000 & & & \\
\hline 3 & Pendapatan & $(22.336 .000)$ & 9.833 .500 & 8.985 .000 & 15.235 .000 \\
\hline 4 & At18\% & 1 & 1,18 & 1,39 & 1,64 \\
\hline 5 & NPV 18\% & $(22.336 .000)$ & & & \\
\hline 6 & Total NPV & 62.914 .450 & & & \\
\hline
\end{tabular}

Sumber : Analisis Data Primer Mei April 2015

Dari tabel diatas dapat diketaui total investasi sebesar $\mathrm{Rp} \quad 22.336 .000$ sehingga diperoleh pendapatan tahun ke 0 adalah $\mathrm{Rp}$ 22.336.000. Dari perhitungan NPV selama empat tahun dengan tingat bunga $18 \%$ maka diperoleh nilai NPV pengolahan mengkudu menjadi sari morinda pada sebesar $\mathrm{Rp}$ 62.914.450 dan nilai NPV > 0 , dengan pengertian usahan pengolahan mengkudu menjadi sari morinda ini menguntungkan dan layak untuk dikembangkan.

\section{b. Analisa IRR (Internal Rate of Return)}

IRR menujukkan kemampuan suatu investasi atau usaha dalam menghasilkan return atau tingkat keuntungan yang bisa dipakai. Kriteria yang dipakai untuk menunjukkan bahwa suatu usaha layak dijalankan adalah jika nilai IRR 
lebih besar dari tingkat suku bunga yang berlaku pada saat usahatani tersebut diusahakan (Gittinger, 1993), jadi, jika IRR lebih tinggi dari tingkat bunga bank, maka usaha yang diusulkan layak untuk di laksanakan.

Tabel 8. Total Analisis Kelayakan Home industry Sari Morinda di Desa Srikaton Kecamatan Buay Madang Kabupaten OKU Timur. (2012-2015).

\begin{tabular}{lllll} 
No Jenis Usaha & NPV $(+)$ & NPV $(-)$ & RR & Net B/C \\
\hline 1 Pengolahan Mengkudu & 4.715 .869 & -260.924 & $35 \%$ & 1,30 \\
\hline
\end{tabular}

Sumber : Analisis Data Primer Mei April 2015.

Berdasarkan hasil olahan data primer diperoleh nilai Net $\mathrm{B} / \mathrm{C}$ sebesar 0,17 lebih besar dari nol (0), bahwa setiap $\mathrm{Rp} \mathrm{1,-}$ yang dikorbankan maka akan meraih keuntungan sebesar Rp 1,30. NPV $\mathrm{P}$ pada tingkat bunga berlaku kini $18 \%$ diperoleh nilai sebesar $\mathrm{Rp}$ 4.715.896. NPV N pada tingkat bunga tertinggi yaitu $35 \%$ diperoleh nilai sebesar Rp - 260.924, maka secara finansial usaha pengolahan mengkudu menjadi sari morinda layak untuk dilaksanakan dan IRR sebesar $35 \%$ lebih besar dari SOCC $18 \%$ maka usaha pengolahan mengkudu menjadi sari morinda layak untuk diteruskan (feasible).

\section{IV.KESIMPULAN DAN SARAN}

\section{A. Kesimpulan}

Berdasarnya hasil penelitian dan analisis yang telah dilakukan, maka dapat ditarik kesimpulan sebagai berikut:

1. Biaya Produksi pengolahan mengkuduku menjadi sari morindan di Desa Srikaton Kecamatan Buay Madang Kabupaten OKU Timur adalah Rp 351.500/ proses produksi. Sedangkan pendapatan Rp 898.500 / proses produksi.

2. Besarnya Nilai Tambah didapat dari nilai produksi dikurangi dengan biaya antara yaitu Rp 991.500 / proses produksi.

3. Pengolahan mengkudu menjadi sari morinda layak untuk dikembangkan dengang kriteria NPV nilai kini home industri sari morinda pada tingkat suku bunga $18 \%$ sebesar Rp 4.715.86 pada tingkat suka bunga tertinggi yaitu $36 \%$ sebesar Rp -260.924maka nilai
NPV > 0 usaha layak untuk dilanjutka. Nilai Net B/C pada nilai NPV yang telah di discount faktor pada usaha home industry sari morinda di dapat sebesar 1,30 dan IRR sebesar 35\%.

\section{B.Saran}

1. Diharapkan agar pelaku usaha hendaknya melakukan proses produksi secara terus menerus dan bisa mencari pangsa pasar sehinga Home industry Sari Morinda dapatt ditingkatkan.

2. Disarankan untuk pemerintah hendaknya mencarikan peluang pasar agar lebih berkembang.

\section{DAFTAR PUSTAKA}

Anonim, 2007. Organisasi Kesehatan Dunia. Penebar Swadaya. Yogjakarta.

$\longrightarrow$ 2013. Pengolahan Sari Morinda. http//www.jevuska.com.

Ar Muhamad. 1983. Pengertian Industri Rumahan. PT. Grafindo Persada. Jakarta.

Drilon Jr dalam Saragih, 1998. Pengertian Agribisnis. Penebar Swadaya. Jakarta

Firdaus, 2008. Strategi Agribisnis. PT. Grafindo Persada. Jakarta.

Hayami, 1987. Nilai tambah. Erlangga. Jakarta.

http://aguskrisnoblog.wordpress.com/2011/06/16/ potensi-olahan-buah-mengkudu-pacesebagai-bahan-hayati-lokal-dalam-upayapengobatan-penyakit-kankerpayudara/ Diakses tanggal 01 Maret 2015.

Kadarsan, 2005. Konsep Pendapatan. Brilian Internasional. Surabaya.

Makfaeld,1982. Pengolahan Mengkudu. Penerba Swadaya. Jakarta.

Maria. 2002. Sehat Dengan Mengkudu. Riset Medis Tentan Mengkudu. Terdapat dalam Situs Web (www.deherba.com/khasihatmengkudu.htm) diakses tanggal 01 maret 2015.

Manulang,2000. Konsep Penerimaan. Gramedia. Jakarta.

Mariliati et all. 1992. Proses sterilisasi. Balai Pustaka. Yokyakarta .

Mauliwan,2002. Konsep Pendapatan. Gramedia. Jakarta.

Moryati,1998.http://herbalindonesia.bis/wpconten t/uploads/2012/05/Alam Sumber Kesehatan Manfaat dan Kegunaan. Balai Pustaka.

Muchtadi, 1995. Proses Seterilisasi. PT. Grafindo Persada. Jakarta. 
Mulyadi, 2002. Konsep Pendapatan. Gramedia. Jakarta Reksohadiprojo, 1992. Proses Produksi. Rineka. Jakarta.

Salmon, 1999. Penyebap Penyakit Batuk. Penerbit PT. Gramedia Pustaka Utama. Jakata.

Saud dan Suarsono, 2004. Studi Kelayakan. Rineka. Jakarta.

Soekartawi, 1995. Analisis Usahatani. UI. Jakarta

Syamsuhidayat. S. S dan Hutapea. R. 1991, Inventaris Tanaman Obat Indonesia. Bahitbangkes. Depkes RI. Jakarta. Diakses tanggal 01 Maret 2015.

Suratiyah,2006. Pengertian Modal. Preenhallindo. Jakarta.
Syarkowi dan Marwan, 2004. Pengertian Agribisnis. PT. Grafindo Persada. Jakarta.

Tampubolon, 1995. Kandungan Utama Buah Mengkudu. Bagian Produksi PT. Mitra Citrifolia Internasional. Jakarta.

Waha, 2002. Pangan, Gizi, Teknologi dan Konsumen. Penerbit PT. Gramedia Pustaka Utama. Jakata.

Yin, R.K. 2008. Studi Kasus Desain dan Metode. Penerjemah, M. Djauzi Mudzaaakir. PT. Raja Grafindo Persada. Jakarta. 